\title{
Applying behavioural economics in education: study of undergraduate practices of selecting higher educational institutions
}

\author{
Velga Vevere $^{1^{*}}$, and Arturs Mons ${ }^{2}$ \\ ${ }^{1}$ EKA University of Applied Sciences, Latvia \\ ${ }^{2}$ Turiba University, Latvia
}

\begin{abstract}
Behavioural economics have become hot topic in research and debate in last few decades. In the context of behavioural economics, it is possible to summarize resemblances and create a system based on predication and regularities of errors, by analysing consumer's behaviour, which allows to solve issues of future process development. In paper "Applying behavioural economics in education: study of undergraduate practices of selecting educational institutions" the authors identify key factors which influence undergraduates to choose higher education institution. The purpose of this paper is therefore to identify key elements of the behavioural economics that can be used to influence undergraduate selection development in favour of higher education institution. Additionally, within the framework of the study are applied insights of behaviour economics, which help guidance general understanding of undergraduate decision making. Particularly focusing on heuristics, that undergraduates are using to ease the complexity of decision making, which can lead to systematic errors and bias. This study per se synopsizes the definite findings of developing behavioural economics, which allows to apply this knowledge to study undergraduate choice in selecting higher educational institution. In this study were used numerous methods, including literature review, interviews with representatives of higher education and behavioural economics experts and surveying undergraduates.
\end{abstract}

\section{Introduction}

Nowadays novel subdivisions of the economics are gaining recognition. There has been one particular subdivision of economics which has gained worldwide attention in past few years - the behavioural economics. Pioneer of it is considered professor at the university of Chicago, Richard Thaler, who received the Noble Prize in Economics in 2017 for his outstanding work in this field. Thaler's research [1,2] has expanded the overall understanding of how individuals think and act when they are involved in economic decision making process and how their characteristics affect the outcome. This belief supported hypothesis that human being acts in his own self-interests, maximizing personal benefits and often profits, therefore always deliberating carefully all decisions.

Most of the 20th century economic was founded on these assumptions. However, another Nobel laureate, Israeli - American psychologist and economist Daniel Kahneman jointly with his peer Amos Tversky [3], made an affirmation that these existing assumptions did not pertain to the reality. Their performed research concluded, that people in decision making process behaved differently, than it was proposed by Smith and

\footnotetext{
* Corresponding author: velga.vevere@gmail.com
} 
Ricardo, predominantly people made irrational and divergent decisions to their own interests. New breakthrough helped to understand the way how man is making decisions. People are manipulating information to make a decision by applying automatic and reflective appraising. Nonetheless, in fast paced situations man does not have time to reflect to possible outcome, therefore impulsive decisions are often made. The conclusions of the researches were appalling to neoliberal society, causing debates about possible ways to make people to perform rational choices. "Nudging" as a method gained wide attention after Thaler and Sunstein published jointly written book "Nudge. Improving Decisions About Health, Wealth, and Happiness" [4], in which it was clarified how a government applied the behavioural economics to daily actions to manage the nation and its citizens. Therefore "nudging" has become a tool of liberal paternalism and is defined as juste milieu between authoritarian bans or penalties and motivation with rewards. Intrinsically changing people behaviour in incessant and encouraging approach to act in a way that would be most beneficial for everybody. With raising recognition of behaviour economics, we can experience its application in more, new fields. One of these fields are considered education, where we can see rise of "nudge" application on its policies in last few years. The movement was started by several countries which introduced "nudging units" in education. Until behavioural economics were broadly recognized, the economics of education was mostly based on the conventional human capital model. This model characteristic is centred on long term contribution towards further education decisions.

The purpose of this paper is to evaluate and reveal student priorities in process of selecting higher education institution. Applying behavioural economics to student higher education selection process improves understanding of how potential students are affected by different means. This comprehension can be applied further in strategies in favour of higher education institutions to influence development of undergraduate selection development.

Psychologists educated society about brain's role as an device for information processing. In 1960's several cognitive models were paralleled to better comprehend human behaviour while making decisions under risks and rationality in economic theory. In late seventies there were published works based on cognitive psychology and explained various differences of decision making process from neoclassical hypothesis viewpoint [5]. In the following two decades researchers focused attention on different factors which could affect decision making process. Simultaneously the behavioural economics gained popularity and it was applied to various fields including the education sector. A number of research was conducted on student behaviour to understand variables which impact the selection of higher education institution $[6,7,8$, 9]. We can find certain similarities between student decision making behaviour and customer buying behaviour [10]. The students segment as part of a market occupies a large share, that is reason why it is stimulating for researchers to collect feedback from.

Numerous factors which influence student behaviour were discovered. Breakthrough was comprehension of uncontrollable and controllable factors, which play major role in student behaviour on higher education selection practices. Location of educational institution, its size good reputation gained importance, once decisions were made. Also external forces which can influence decision making processes - family, teacher and friends need to be taken into account. Associations were found when researched parental education on undergraduates' education, large share generation correlation have similar relations [11]. Teaching staff's influence is also present when it comes to undergraduate future selection practices in favour of institution [12]. The choice of study subject, it was found, depends on evaluation of long term benefits, also the financial aspects are taken in consideration. Undergraduates apply different frameworks, such as economical and theoretical, to observe impact factors to select the right higher education institution. 
Mazzarol and Soutar [13] have defined six influential "push and pull" factors which affect the selection practices. The important factors which power the final decision are more linked to the individual's subjective characteristics. The researchers have discovered that parental involvement, financial benefits, higher educational institutions location, institutions reputation and well as study programs satisfaction ratio are amongst leading influential factors. Financial support of study process always has played important factor to undergraduates and their families. Higher Educational Institutions with provided financial support system are more significant to prospective students. The current economic situation has challenged many students with availability to afford study tuition fees. Chatfield et al. [14] distinguished clear difference between enrolment fees and financial support. The study explains that financial support of higher education institution can be in form of deducted tuition fees or funding's which are designed to cover these expenditures. Study program and Higher Education Institutions reputation are also among "push and pull" factors. Knowledge and awareness of these factors significantly ease outcome of decision. It's agreeable that cultural background plays major role on importance of selected study program. The present status and prestige of higher education institutions is motivator to undergraduate lean towards one or another institution. Universities and other higher education institutions are investing lots of efforts to maintain reputation and boost the academic prestige, what can lead to more prospective admittees [15]. Accordingly, better reputation and higher ranking ensure higher education institution a competitive advantage in present education market. It is important to sustain good public image, it subjective reflects actions performed internally in the institution. Social influence impacts human behaviour in all situations of decision making process. People tend to make more spontaneous and risky decisions when they are part of a group [16]. Fershtman and Segal [17] have discussed phenomena of tendencies for a group to make decisions which are irrational and in distinctive circumstances would be opposing the personal interests.

\section{Methods}

The aim of this study is to enhance previous academic researches and develop enriched understanding of undergraduate decision making practices. Following the widely growing interest of nudging and behavioural economics which are applied in numerous governments worldwide, the authors explored empirical evidence to discover key factors which influence undergraduate selection practices for higher education institutions. These findings give the authors foundation to create possible applicable "nudges", which higher education institutions can apply to gain competitive advantage in current saturated education market and attract more prospective students.

This study has taken non experimental approach by surveying respondents to create descriptive research. The samples were selected randomly. To collect primary data was designed an online self-administrative questionnaire, that was adapted version of Europe International Student Survey 2017. Sample of 158 respondents from 46 countries, which contained undergraduates from assortment of ethnicity, was undertaken. The study was conducted in period of July 2019 to August 2019, which data is used to report the findings of the study. Respondents were undergraduates who actively applied to join higher education institution. The sample contained following ratio $-70.9 \%$ female and $29,1 \%$ male respondents, all surveyed respondents being at legal age of 18 or above.

The research question of the current investigation is: What are the key factors which influence undergraduate selection practices in favour of higher education institutions? 


\section{Results and discussion}

In order to understand undergraduate practices of selecting higher education, firstly authors attempt to discover factors which motivates prospective students to continue educational development. Undergraduates were provided with sixteen possible motivational factors and they were asked to select three of them, which they consider as key factors for their motivation (see Figure 1).

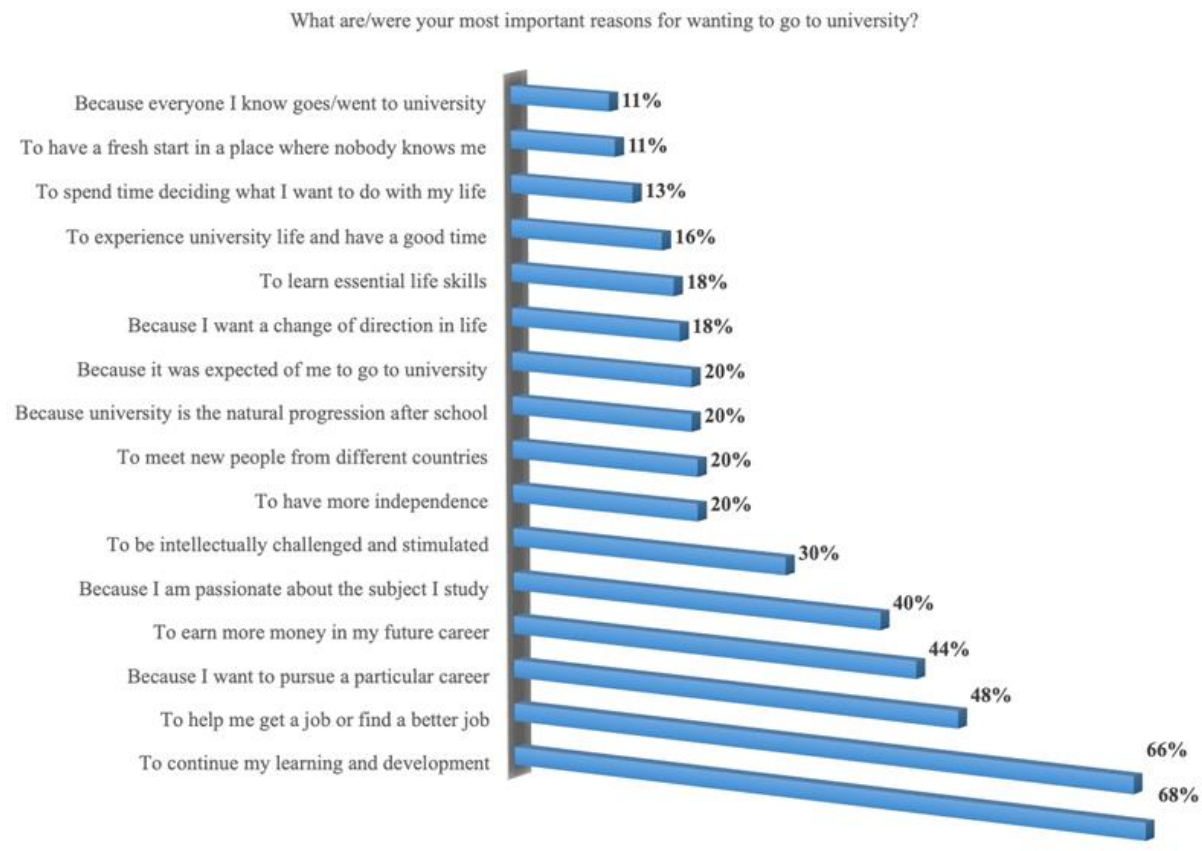

Fig. 1. Motivation for Studying

It was discovered that the most encouraging factors to continue studies were urge for educational and personal development with $68 \%$ in rating what is one of top three causes. The second most influential motivation is confidence that education would assure employment or development in career $(66 \%)$, followed by particular need for exact education to pursue the selected career path with $48 \%$. The factor applied in the selection also depends on individual's characteristics, big role in this selection plays emotive language. However, next runner up in selected factors is motivation for monetary benefits in future. Learning motivational reason for undergraduates to pursue further higher education, authors study influences which undergraduate needs to face by selecting potential higher education institution. Respondents were asked to give opinion on choices which they need to proceed with during decision making process. There were collected opinion on four key areas: Course, country, university and location (see Figure 2). 


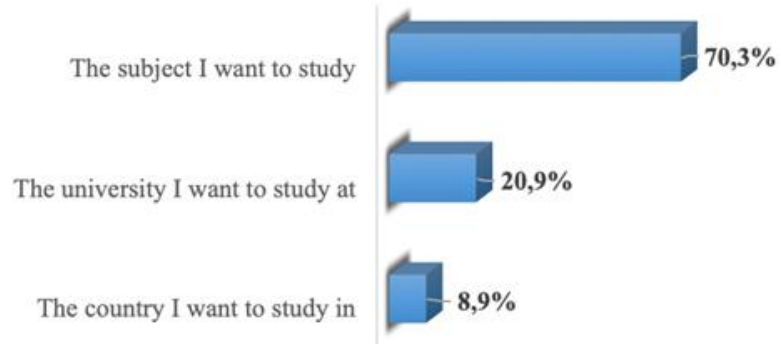

\section{Fig. 2. Decision Order}

The majority of undergraduates selected as priority option a subject of study, followed by higher education institution, then location. These findings give us the understanding on what are the main motivating factors in study selection. The undergraduates were asked to select five most important factors, out of eleven provided selection options, in decision making process in favour for study subject (see Figure 3).

What five things are most important to you when choosing a study program?

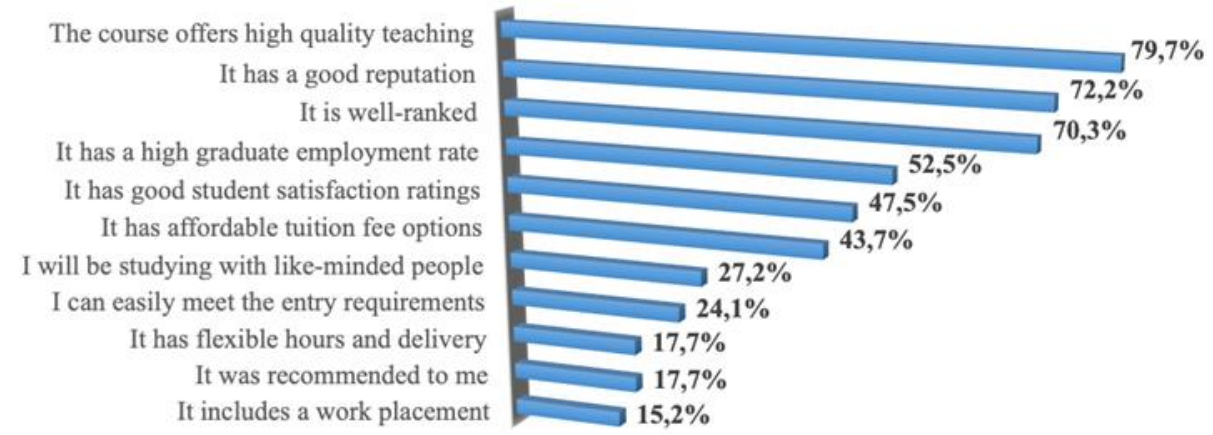

Fig. 3. Decision making key factors in favour for study program

Once undergraduates were given choice to select five most important factors which they take into account once performing a study subject selection were discovered following: Main focus is set on teaching quality, which was most selected factors leading the rank with $79,7 \%$. Followed by reputation of the study program with $72,2 \%$ and rank of the program with $70,3 \%$. In the study it was discovered that, when undergraduates select location of the higher educational institution, country or town, most attention were based on: Location must have higher educational institutions with high ranking and excellent teaching quality, place has good reputation and it is welcoming to international community. Great share of decision take safety aspect of the location, provided recreational possibilities and cost of living. The following figure depicts factors, which affect undergraduate once they select higher educational institution. Factors which determine they selection in favour to one or another higher education institution (see Figure 4). 
What five things are most important to you when choosing a university?

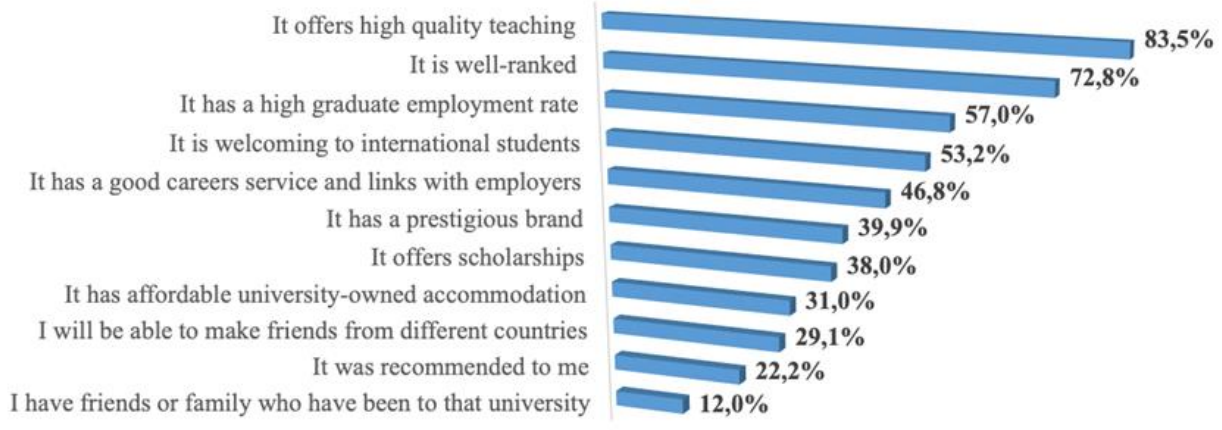

Fig. 4. Decision making key factors in favour for study program

The dominant factor is teaching quality in which university is performing study programs with $83,5 \%$, second prominence is higher education institutions ranking with $72,8 \%$. Furthermore, significant factor for undergraduates is high employment rate after study finalizing, which gives the assurance for further professional career development. In order to understand where higher education institutions can apply "nudges" to influence undergraduate selection practices, further investigation was demanded. Respondents were asked to compare higher education institution rank against study quality, to apprehend which associations they have with high quality teaching. Undergraduates were asked to choose one of two provided options to cognize which factor is more influential. Higher education institution rankings have played big role in selection practices, however, study was needed to understand if it has as high value of importance as it is propounded by general society. Study revealed that undergraduates will select higher education institution with high teaching quality $(60,8 \%)$ over institution with high ranking $(39,2 \%)$. It gives us clear indication that propounded belief that institution ranking is playing dominant role was deceptive.

Survey participants were requested to rate five provided factors to understand what in their opinion indicates high teaching quality in higher education institutions. More than a half or $56,3 \%$ of respondents strongly agreed on that higher educational institutions with highly qualified teaching staff is dominant metre, followed by $27,8 \%$ of respondents somewhat agreeing. Total of $84,1 \%$ of respondents agreed on this factor as resilient indicator what also took foremost top place amongst all factors. Next significant factor what in respondent's view indicates high teaching quality is high post graduate employment rates. Total of 77,2\% agreed on this factor, leading it to second most important indicators place (see Table 1).

Table 1. Quality Factors of Higher Education Institution

\begin{tabular}{|l|c|c|c|c|c|}
\hline Teaching staff are highlyqualified & $\begin{array}{c}\text { Strongly } \\
\text { agree }\end{array}$ & $\begin{array}{c}\text { Somewhat } \\
\text { agree }\end{array}$ & $\begin{array}{c}\text { Neither agree } \\
\text { nor disagree }\end{array}$ & $\begin{array}{c}\text { Somewhat } \\
\text { disagree }\end{array}$ & $\begin{array}{c}\text { Strongly } \\
\text { disagree }\end{array}$ \\
\hline A high graduate employment rate & $56,3 \%$ & $27,8 \%$ & $5,1 \%$ & $5,1 \%$ & $5,7 \%$ \\
\hline Up-to-date technology and online learning options & $41,1 \%$ & $36,1 \%$ & $12,7 \%$ & $5,1 \%$ & $5,1 \%$ \\
\hline The university organises work placements & $39,2 \%$ & $37,3 \%$ & $12,0 \%$ & $7,6 \%$ & $3,8 \%$ \\
\hline High volume of face-to-faceteaching hours & $29,7 \%$ & $32,9 \%$ & $25,9 \%$ & $10,1 \%$ & $1,3 \%$ \\
\hline
\end{tabular}

Higher education institutions need to define right areas where to apply "nudges" to gain maximum result. By providing incompetent information, higher education institutions are risking to lose valuable undergraduates, also forfeit competitiveness in the education market. Delivering right "nudges" will make higher education institution more desirable 
and appealing to prospective students. The current approaches of providing information by higher education institutions does not always meet undergraduate needs by covering areas of interest. Not receiving desired information, it can leave undergraduate in doubt of selecting the right institution. Survey results displays clear focus areas where applying "nudges" would influence undergraduate decision making process and final choice. Information presented needs to be relevant, from the time when undergraduate is doing research, it is a first connection between institution and applicant. Therefore, information must reflect undergraduate's areas of interest by supporting applicable knowledge. Such areas as updated data about the study program, its context and customization options, flexibility, employment rate after completing education, overall teaching quality higher education institutions must provide. Importance also must be assigned to displaying applied teaching methods during the study program, as well as how welcoming is location and institution to foreign students. By enlightening undergraduates about areas of their interest it will ease their decision making process in favour of most appealing institution, by most relevant information provided. In academia has been performed many researched in order to discover successful promotion strategy for higher education institutions. The undergraduates value not only educational aspects but also social, recreational possibilities provided by location of selected higher education institution. Such knowledge of factors plays dominant role once the decision making is in final phase, by supporting this data from very beginning it allures prospective undergraduates.

\section{Conclusion}

In the current global higher education market state higher education institutions need to emphasis undergraduate needs more than ever. Market being saturated does not give much space for errors. In competitive environment it is crucial to find new ways to allure undergraduates to enrol in study programmes. The empirical research reports on small size sample, however, it gives us improved understanding of current situation. The study shows key factors and areas where higher education institutions can apply "nudges" to guide undergraduates in favour of institution. Current study reports on findings, which are relatively simple, however, demands elaboration. Undergraduates are keen to receive input in conserving areas such as teaching quality, course adaptability to personal needs and postgraduate employment rates.

By discovering factors "nudge" needs to be built in a way that it stimulates freshman's views. However, the purpose of this study was to recognize key factors which influence undergraduate selection practices in favour of higher education institutions. By identifying these aspects higher education institutions are able to develop appropriate "nudges" to influence undergraduate selection performance. Significant role is taken by individual' $\mathrm{s}$ characteristics and emotional state, which influences decision making process. It is important to keep in mind while people are logical beings to the great extant, we are more impacted to emotions what can influence to act in a way which might not be rational. By applying principles of behaviour economics and the study findings higher education institutions are able to develop more affective "nudges" to impact undergraduate decision process.

\section{References}

1. R. H. Thaler, Behavioural Economics. Journal of Political Economy 125, 17991805 (2017) 
2. R. H. Thaler, Nudge, not Sludge. Science 361, 431 (2018)

3. D. Kahneman, A. Tversky, The rational choice, values and frames. Psikhologicheskii Zhurnal 24, 31-42 (2003)

4. R. H. Thaler, C. R. Sunstein, Nudge. Improving Decisions About Health, Wealth, and Happiness (Yale University Press, New Haven, CT, 2008)

5. D. Kahneman, A. M. Rosenfield, L. Gandhi, T. Maser, Reducing Noise in Decision Making. Harvard Business Review 94, 8-18 (2016)

6. R. Fazli-Salehi, M. Esfidani, I. Torres, M. Zúñiga, Antecedents of students' identification with university brands A study on public universities in Iran. Asia Pacific Journal of Marketing and Logistics 31, 830-854 (2019)

7. A. Merchant, G. M. Rose, G. Moody, L. Mathews, Effect of University Heritage and Reputation on Attitudes of Prospective Students. International Journal of Nonprofit and Voluntary Sector Marketing 20, 25-37 (2015)

8. N. Rika, J. Roze, I. Sennikova, Factors Affecting The Choice of Higher Education Institutions by Prospective Students in Latvia. CBU International Conference Proceedings 2016: Innovations in Science and Education. Prague, Central Bohemia Univ, Unicorn College (2016)

9. $\mathrm{P}$. Yu, The stratification of higher education in the USA and Taiwan: a comparative analysis of students' college-choice outcomes. Compare-A Journal of Comparative and International Education 49, 700-722 (2019)

10. P. Kotler, G. Armstrong, Principles of Marketing. Global Edition (Pearson Education Limited, Harlow, 2015)

11. H. Holmlund, M. Lindahl, E. Plug, The Causal Effect of Parents' Schooling on Children' Schooling: a Comparison of Estimation Methods. Journal of Econ. Lit. 49, 615-651 (2011)

12. I. Dalc1, H. Arasl,, M. Tumer, S. Baradarani, Factors that influence Iranian students' decision to choose accounting major. Journal of Accounting in Emerging Economies 3, 145-163 (2013)

13. T. Mazzarol, G. Soutar, The Push-Pull Factors Influencing International Student Selection of Education Destination. International Journal of Educational Management 16, 82-90 (2002)

14. H. K. Chatfield, S. J. Lee, R. E. Chatfield, The Analysis of Factors Affecting Choice of College: A Case Study of University of Nevada Las Vegas Hotel College Students. Journal of Hospitality \& Tourism Education 24, 26-33 (2012)

15. F. Vught, Mission Diversity and Reputation in Higher Education. Higher Education Policy 21, 151-174 (2008)

16. E. Aronson, E., T. D. Wilson, D., R. M. Akert Social Psychology (Prentice Hall, Upper Saddle River, 2010)

17. C. Fershtman, U. Segal, Preferences and Social Influence. American Economic Journal-Microeconomics 10, 124-142 (2018) 